\title{
Contribution to the study of cutting temperature and tool wear
}

\author{
M. Bourdim, M.B. Djillali, L. Zouambi, B. Bloul \\ University Ahmed Zabana Relizane- Algeria
}

\begin{abstract}
The quality of a machined part strongly depends on the state of wear and the cutting tool. This wear is a major problem in the field of industry. This depends on several factors such as the material to be machined, the cutting tool, the cutting conditions and the machining process. All these factors have the corollary of a significant production of heat at the tool-chip interface. This heat induces accelerated wear of the cutting tool, which considerably limits the performance of the machine tool and is mainly detrimental to both the workpiece and the cutting tool. In this study, the main objective is to contribute to the study of the mechanisms of degradation of the tool by carrying out from an experimental approach based on the techniques of thermocouples located in places studied in order to avoid the influence of parasitic and undesirable parameters such as surface regeneration vibrations, etc. This approach is carried out experimentally by measuring the temperature of the cutting face (friction tool / chip interface). From the results collected during the experiment, we can understand the effects of different turning parameters on the temperature developed on the face of the tool and the appropriate turning conditions to obtain a maximum material removal rate at a lower temperature. The results obtained are represented and analyzed graphically.
\end{abstract}

Keywords - cutting, tool, work piece, temperature, thermocouple, cutting forces, feed, productivity.

\section{INTRODUCTION}

I cutting, nearly all of energy dissipated in plastic deformation is converted into heat that in turn raises the temperature in the cutting zone [1]. Since the heat generation is closely related to the plastic deformation and friction, we can specify three main sources of heat when cutting, Fig. 1.

1) Plastic deformation by shearing in the primary shear zone

This work was supported in part by the U.S. Department of Commerce under Grant BS123456 (sponsor and financial support acknowledgment goes here). Paper titles should be written in uppercase and lowercase letters, not all uppercase. Avoid writing long formulas with subscripts in the title; short formulas that identify the elements are fine (e.g., "Nd-Fe-B"). Do not write "(Invited)" in the title. Full names of authors are preferred in the author field, but are not required. Put a space between authors' initials.

F. A. Author is with the National Institute of Standards and Technology, Boulder, CO 80305 USA (corresponding author to provide phone: 303-5555555; fax: 303-555-5555; e-mail: author@ boulder.nist.gov).

S. B. Author, Jr., was with Rice University, Houston, TX 77005 USA. He is now with the Department of Physics, Colorado State University, Fort Collins, CO 80523 USA (e-mail: author@lamar. colostate.edu).

T. C. Author is with the Electrical Engineering Department, University of Colorado, Boulder, CO 80309 USA, on leave from the National Research Institute for Metals, Tsukuba, Japan (e-mail: author@nrim.go.jp). (heat source Q1).

2) Plastic deformation by shearing and friction on the cutting face (heat source Q2).

3) Friction between chip and tool on the tool flank (heat source Q3).

Heat is mostly dissipated by,

1) The discarded chip carries away about $60 \sim 80 \%$ of the total heat (q1).

2) The workpiece acts as a heat sink drawing away $10 \sim 20 \%$ heat (q2).

3) The cutting tool will also draw away $\sim 10 \%$ heat (q3).

4) If coolant is used in cutting, the heat drawn away by the chip can be as big as $90 \%$ of the total heat dissipated.

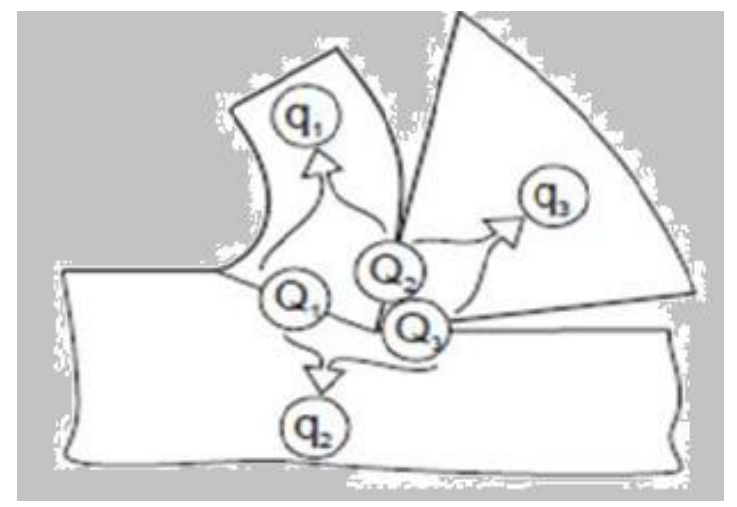

Fig. 1 Balance of heat generation and heat dissipation in metal cutting

Knowledge of the cutting temperature is important because it:

1) Affects the wear of the cutting tool. Cutting temperature is the primary factor affecting the cutting tool.

2) Can induce thermal damage to the machined surface. High surface temperatures promote the process of oxidation of the machined surface. The oxidation layer has worse mechanical properties than the base material, which may result in shorter service life. 
Causes dimensional errors in the machined surface. The cutting tool elongates as a result of the increased temperature, and the position of the cutting tool edge shifts toward the machined surface, resulting in a dimensional error of about $0.01 \sim 0.02 \mathrm{~mm}$. Since the processes of thermal generation, dissipation, and solid body thermal deformation are all transient, sometime is required to achieve a steady-state condition.

\section{CUTTING TEMPERATURE DETERMINATION}

Cutting temperature is either. Measured in the real machining process, or

1) Predicted in the machining process design.

The mean temperature along the tool face is measured directly by means of different thermocouple techniques, or indirectly by measuring the infrared radiation, or examination of change in the tool material microstructure or microhardness induced by temperature. Some recent indirect methods are based on the examination of the temper colour of a chip, and on the use of thermosensitive paints. There are no simple reliable methods of measuring the temperature field. Therefore, predictive approaches must be relied on to obtain the mean cutting temperature and temperature field in the chip, tool and work piece. For cutting temperature prediction, several approaches are used:

2) Analytical methods: there are several analytical methods to predict the mean temperature. Due to the complex nature of the metal cutting process, the analytical methods are typically restricted to the case of orthogonal cutting.

3) Numerical methods: These methods are usually based on the finite element modeling of metal cutting. The numerical methods, even though more complex than the analytical approaches, allow for prediction not only of the mean cutting temperature along the tool face but also the temperature field in orthogonal and oblique cutting.

\section{CUTTING TEMPERATURE CONTROL}

The temperature in metal cutting can be reduced by:

1) Application of cutting fluids (coolants).

2) Change in the cutting conditions by reduction of cutting speed and/or feed.

3) Selection of proper cutting tool geometry (positive tool orthogonal rake angle).

Apart from application of coolants, the simplest way to reduce the cutting temperature is to reduce the cutting speed and/or feed. The next diagrams show the dependencies between the mean cutting temperature and cutting conditions, Fig. 2.

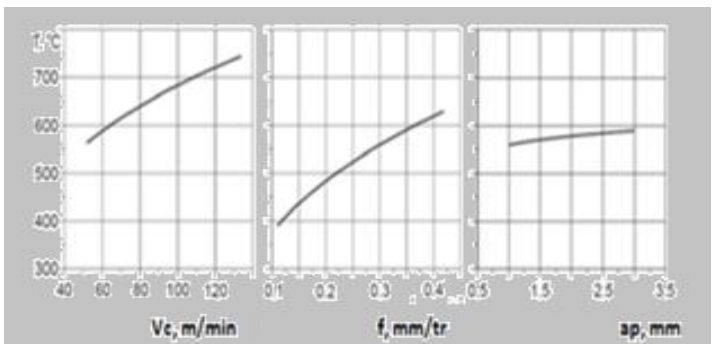

Fig. 2 Cutting temperature as a function of cutting speed, feed and depth of cut d [1]

\section{EXPERIMENTAL DEVICE}

\section{1) Machine tool and thermocouple position}

The Fig. 3, represents the entire apparatus used for both test series. A tour REALMECA T400 digital control power 7.5 kilowatts is used to perform the shooting test [2].

Specially formed artificial thermocouple was placed between shim and insert on the spot below cutting zone.

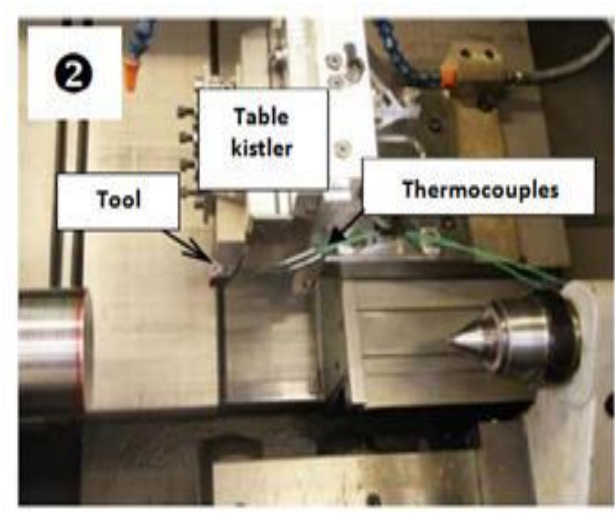

Fig. 3 General view of the machining [2]

\section{2) Workpiece material to be machined}

The material is machined from steel C45, used in industry (aeronautics, automotive, engineering,). These are steel bars, obtained by drawing, of $100 \mathrm{~mm}$ diameter [2].

The "table 1" summarizes the chemical composition of the material selected. 
Table 1 Chemical composition and mechanical properties of the machined material.

\begin{tabular}{|l|l|l|l|l|l|l|l|l|l|}
\hline Elements & C & Si & Mn & P & S & Cr & Ni & Mo & Cu \\
\hline $\begin{array}{l}\text { Content in } \% \\
\text { mass }\end{array}$ & 0,45 & 0,22 & 0,66 & 0,027 & 0,032 & 0,26 & 0,15 & 0,02 & 0,18 \\
\hline $\begin{array}{l}\mathrm{Re} 0,2 \% \\
\mathrm{MPa}\end{array}$ & & & & & 437 & & & & \\
\hline $\mathrm{Rm}$ & & & & & 704 & & & & \\
\hline $\mathrm{A} \%$ & & & & & 20,6 & & & & \\
\hline
\end{tabular}

\section{3) Cutting conditions}

The cutting conditions were determined according to the requirements and recommendations of Sandvik.

Cutting speed: $100 \leq \mathrm{Vc} \leq 400 \mathrm{~m} / \mathrm{min}$,

Feed rate $\mathrm{f}=0,15 \mathrm{~mm} / \mathrm{tr}$,

Depth of cut ap $=1,2 \mathrm{~mm}$.

\section{4) Cutting tool}

The cutting tool, Fig. 4 is formed of a triangular plate irreversible titanium carbide coated type TNMG 160408 and a door designation tool SOGIMO $90^{\circ} 20 \mathrm{~W} 3 \mathrm{~K} 10$ a following geometry:

$$
\psi=95^{\circ} ; \alpha=6^{\circ}, \gamma=-6^{\circ}
$$

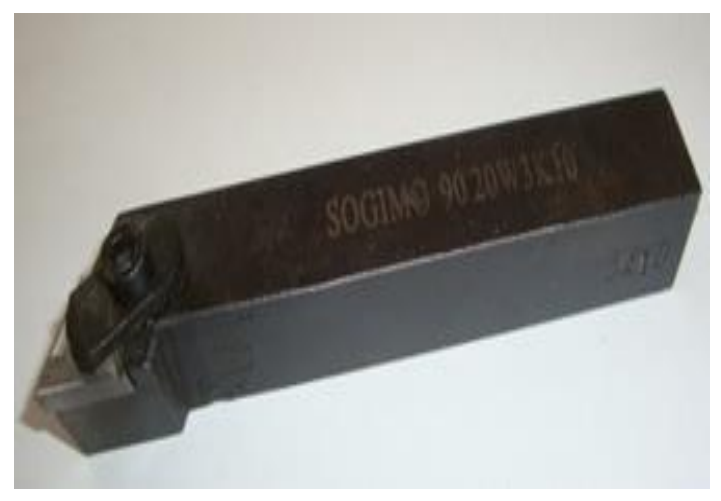

Fig. 4 Plate and insert

\section{5) Methodology of the experimental study}

A COM (Couple-tool-materials), as defined by the NF E66$520-4$, is a method usually used to obtain a qualification point and subsequently determine the steady cutting area where phenomena like vibration, surface regeneration will have almost no influence on the wear mechanisms to study.

In turning, determination beaches stable cutting parameters (Vc, f, ap) is based on the variation of specific cutting forces, calculated by "Eqs. (1), (2) And (3)".

$$
K_{C}=\frac{F_{C}}{f . a p}
$$

$$
\begin{gathered}
K f=\frac{F_{f}}{f \cdot a p} \\
K p=\frac{F_{p}}{f \cdot a p}
\end{gathered}
$$

With $\mathrm{Kc}, \mathrm{Kc}$ and $\mathrm{Kp}$ the specific cutting forces due respectively to the cutting force $(\mathrm{Fc})$ in the effort to advance (Ff) and the penetration force (Fp).

In general, the cutting speed is one of the parameters that provides the greatest energy to the system and greatly influences the damage of the tool.

The more flow measurement or temperature during the process is critical to the understanding of the machining and quality control of the workpiece. It is one of the methods used to monitor machining. This measure is important in industry circles and research $[3,4$, and 5].

\section{RESULTS AND DISCUSSION}

The experimental results presented in this section, shows clearly the temperature level and the influence of cutting conditions on the temperature evolution in the cutting tool. Fig. 5, shows the changes in temperatures in the cutting tool face measured by the thermocouples TC1 and TC2 for a cutting speed of $100 \mathrm{~m} / \mathrm{min}$ and test duration of $100 \mathrm{~s}$. For this cutting speed, the measured temperatures remain transient for duration of about $20 \mathrm{~s}$ cut. The rapid increase in the first moments of cut is due to the complete consumption of thermal energy for the change of state of the wafer (hot-cold state condition). Beyond this cutting time (20s), the temperature is very slowly increasing. This low growth may be due to wear of the cutting tools during machining because the thermocouplecontact surface distance decreases. The gap between changes in TC1 and TC2 temperature remains practically constant in the period of low growth. This difference is about $60^{\circ} \mathrm{C}$. The maximum temperature in the tool is about $400{ }^{\circ} \mathrm{C}$ for the thermocouple TC1 which is the closest to the cutting face. 


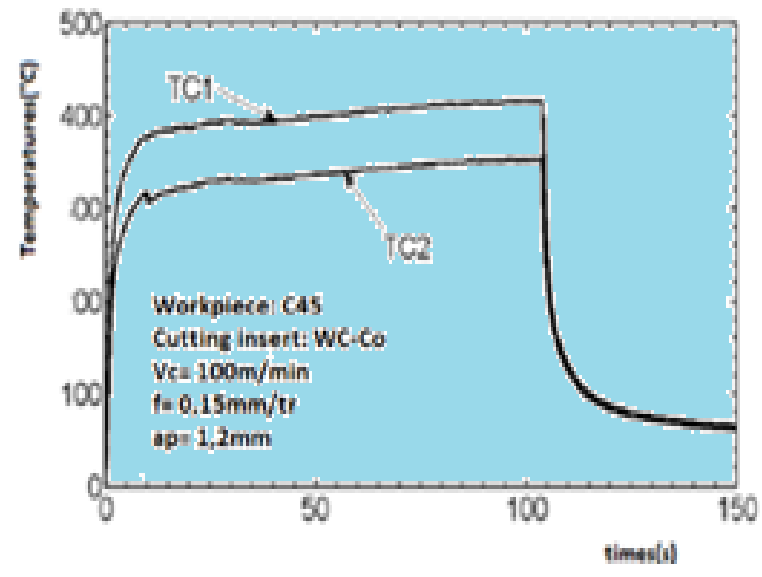

Fig. 5 The temperature developments in the tool versus time, $\mathrm{Vc}=$ $100 \mathrm{~m} / \mathrm{min}$, (TC1 and TC2 are respectively $0,5 \mathrm{~mm}$ and $1 \mathrm{~mm}$ from cutting face)

The Fig. 6, represent the evolution of temperatures measured with time for the cutting speed of $320 \mathrm{~m} / \mathrm{min}$. The observation of this figure shows that after machining $10 \mathrm{~s}$, the temperature is still in a transitional regime. This confirms previous observations on the evolution of temperatures in the case of $100 \mathrm{~m} / \mathrm{min}$. For the case of $350 \mathrm{~m} / \mathrm{min}$, the maximum temperature recorded by the thermocouple $\mathrm{TC} 1$ is about $398^{\circ} \mathrm{C}$. This temperature is nearly equivalent to that obtained for the cutting speed of $100 \mathrm{~m} / \mathrm{min}$ after $100 \mathrm{~s}$ of cutting time. This shows the influence of the cutting speed on the temperature level in the tool. This aspect will be a more detailed analysis later. These temperature levels are also obtained by Filice et al. $[6,7,8]$ during the machining of $\mathrm{C} 45$ steel (AISI 1045) with a WC-Co tool and cutting conditions of $\mathrm{Vc}=200 \mathrm{~m} / \mathrm{min}, \mathrm{f}=0.2 \mathrm{~mm} / \mathrm{tr}$, ap $=3 \mathrm{~mm}$. The same trends are observed in the work of Ay and Yang [9- 10-11-12] during the machining of $\mathrm{C} 45$ with WC-Co tools for cutting.

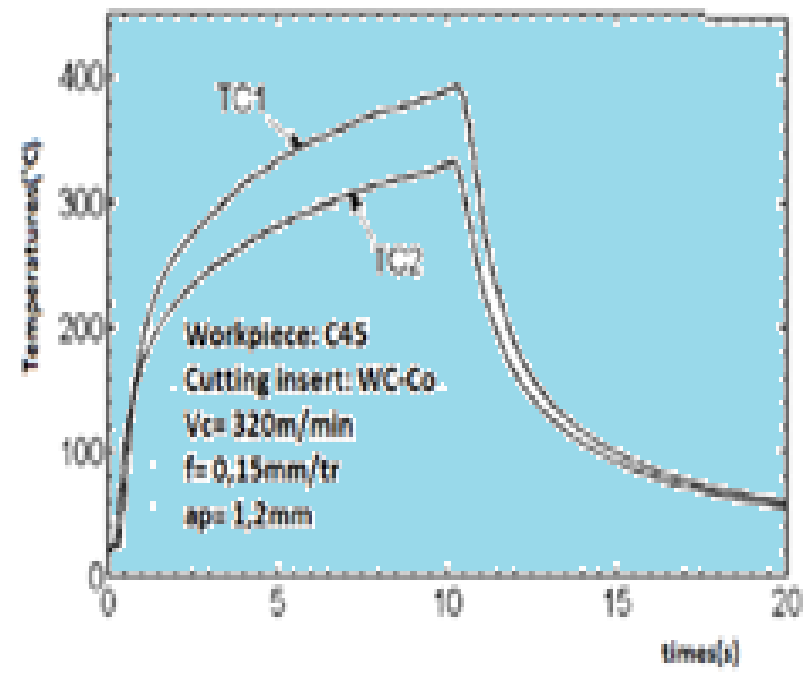

Fig. 6 Evolution de la température dans l'outil en fonction du temps : $(\mathrm{Vc}=400 \mathrm{~m} / \mathrm{min}$, ap $=1,2 \mathrm{~mm})$

The Fig. 7, illustrates another example of changes in temperatures of the cutting tool for a cutting speed of $400 \mathrm{~m} /$ min. 30s after machining, the temperature is still in the transitional regime but there is appearance of fluctuations and temperature changes on the curves. These disturbances are due to wear of the tool. This case will be presented in the next section in comparison with the cutting forces. The maximum temperature recorded by the thermocouple closest to the front section (TC1) is $822^{\circ} \mathrm{C}$. This level of temperature in the tool is high and contributes to the wear of the latter. Data $\mathrm{Vc}=116$ $\mathrm{m} / \mathrm{min}, \mathrm{f}=0.05 \mathrm{~mm} / \mathrm{tr}$, ap $=0.25 \mathrm{~mm}$.

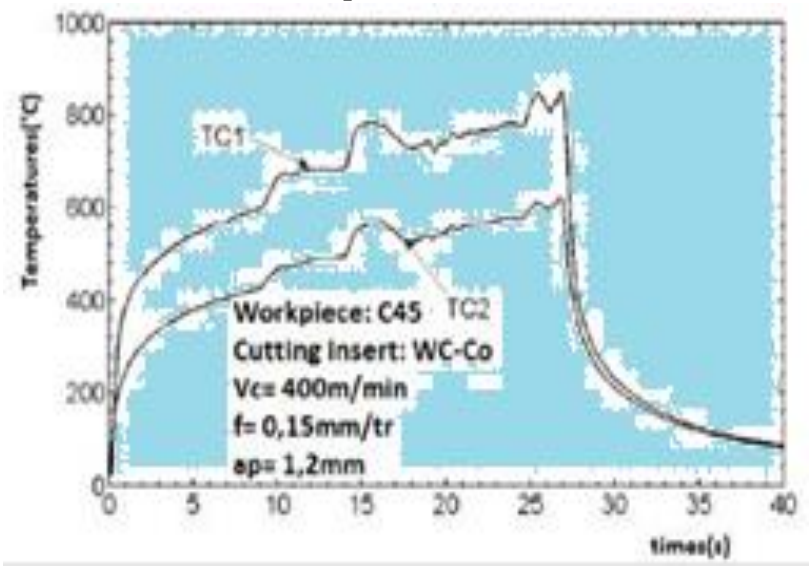

Fig. 7 The temperature developments in the tool versus time, $\mathrm{Vc}=$ $100 \mathrm{~m} / \mathrm{min}$, (TC1 and TC2 are respectively $0,5 \mathrm{~mm}$ and $1 \mathrm{~mm}$ from cutting face)

The Fig. $8 \mathrm{~A}$ and $\mathrm{B}$ ", represents developments of the maximum temperatures of the cutting tool to different cutting speeds and at given time intervals. The gait of temperature trends are the same for both thermocouples. For from 100 to $300 \mathrm{~m} / \mathrm{min}$ speed, increasing the temperature beyond $10 \mathrm{~s}$ is less significant. In contrast to the speed of $400 \mathrm{~m} / \mathrm{min}$, the increase is considerably greater. These temperature measurements confirm that there are two Pad Wear diets: a low or medium wear regime for lower cutting speed up to 300 $\mathrm{m} / \mathrm{min}$ and a wear catastrophic regime beyond $400 \mathrm{~m} / \mathrm{min}$.
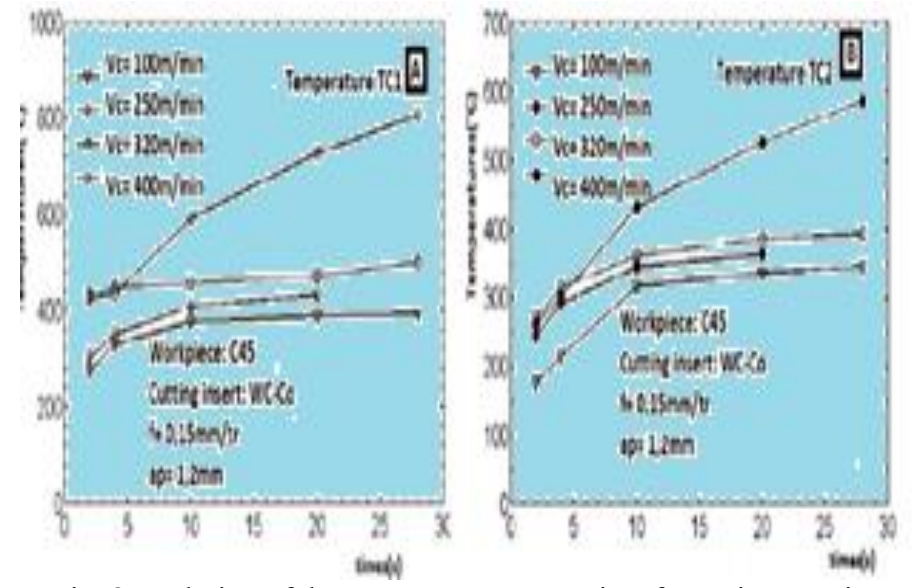

Fig. 8 Evolution of the temperature versus time for various cutting speeds TC1and TC2

The Fig 9, shows the evolution of the temperature in the tool 
for the case of a cutting speed of $250 \mathrm{~m} / \mathrm{min}$ and for four successive cutting passes. The indexed line 3 shows that the maximum temperature level increases with each cutting pass (when compared with the indexed line 2). This increase may be due to inertia and the heat of residue discharged in the wafer (better thermocouple response time in the case of an already machined wafer, the temperature stabilization at the end of a pass since the ridges lower remain substantially on the same line (1)). The increase may also be due to wear of the tool, is to the dimensional variation of the thermocouple position. The shape in the temperature cycles in the case of multi-pass machining also suggests that thermal fatigue phenomena may also influence the wear of the cutting tool.

To understand the fluctuations and jumps seen in Figure 6, simultaneous analysis of developments efforts and temperature is presented in the following paragraph. It is known that sudden fluctuation in the cutting force and temperature of the cutting tool is associated with a degradation of the cutting tool. This link is the main basis for monitoring the machining [1314].

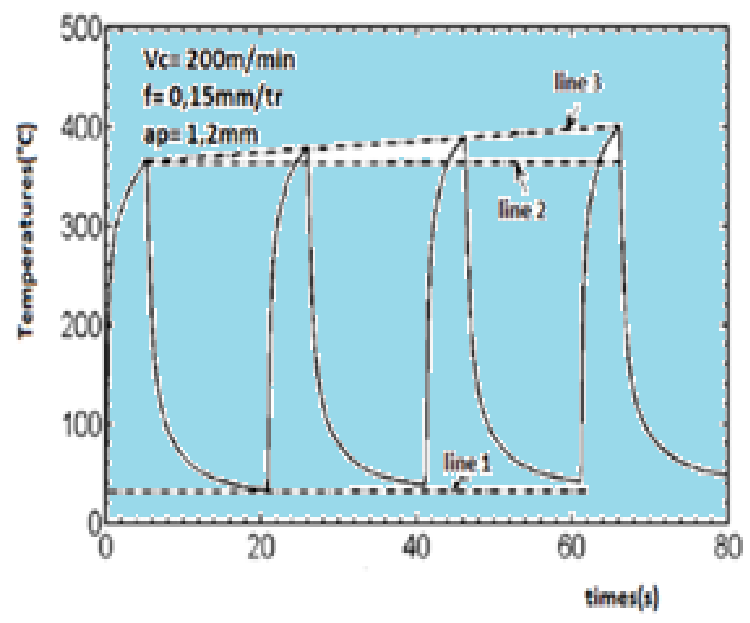

Fig. 9 Evolution of the temperature in the tool according to the number of passes

Fig. $10 \mathrm{~A}$, shows the evolution of cutting force versus time for the speed of $400 \mathrm{~m}$ cuts / $\mathrm{min}$. These developments have instantaneous variations efforts due to wear (chips) of the cutting edge and these variations are more pronounced on the advancing effort. Indeed, the section of the chip is the product of the depth of cut in advanc e (ap. f). This implies that a wear of the edge results in a higher cutting resistance in the direction of movement of the tool in the cutting direction. The magnitude of the "jumps" is seen as more important in the effort to advance (Ff) for the cutting force $(\mathrm{Fc})$. comparison between changes in temperature and changes in advance of effort illustrates that the detection of the fluctuations in advance efforts coincide with fluctuations in temperatures, "Figure 10 B".

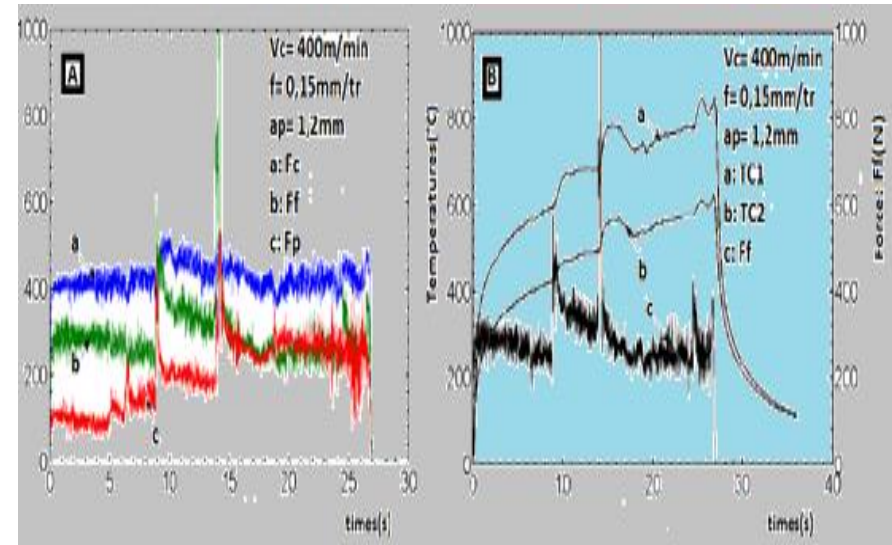

Fig. 10 Efforts evolutions versus time and the temerature and effort as a function of time

\section{CONCLUSIONS}

These temperature measurement results help us better understand the exchange of the temperature at the interface tool / chip. Its also used to highlight scientific and technological obstacles encountered in science and industry that are especially linked:

1) The behavior of the material being machined and the tool as well as interactions between them.

2) For determining the temperature level generated during machining and the effect of temperature in the machining process, particularly on the wear of cutting tools.

\section{Acknowledgement}

This work falls within the framework of my thesis of magister titled contribution to the study of the integrity of the state of on-face machined in hard shooting. The authors would like to thank the Laboratory for Water and Environmental Engineering (EOLE) of the Faculty Technical Sciences, University Abou Bek Belkaid of Tlemcen for the support provided in this research. 


\section{References}

[1] V. Marinov. Manufacturing Technology

2016.

[2] M. Bourdim. (2007, August). Contribution to the study of the integrity of the machined surface condition in hard turning, M. S. Thesis, Department of Mechanical Engineering, Higher Technical School, Oran, ALGERIA. 2007.

[3] R. - G. Ahmed, M. Yovanovich, M. Experimental study of forced convection from isothermal circular and square cylinders and toroids. Journal of Heat Transfer, pp. 422-438. 1997.

[4] H.A. Abdallah, M. El Mansori. Tribo energetic correlation of tool thermal properties to wear of wc- co inserts in high speed dry machining of aeronautical grade titanium alloys". Wear, 415. pp. 432-443. 2009.

[5] W. Grzesik, L.C.A. Van. Analytical models based on composite layer for computation of tool-chip interface temperatures in machining steels owith multilayer coated cutting tools". Manufacturing Technolgy, 54(1), pp. 91-94. 2005.

[6] A. -J. Shih. Finite element analysis of the rake angle effects in orthogonal metal cutting". International Journal of Mechanical Sciences, pp. $1-17$. 1996.

[7] M.C. Shaw. Metal Cutting Principles, 6th Edition, Oxford University Press, London, England, pp. $32-37$ (1984).

[8] G. Tantussi. Sensor integrated tool for cutting force monitoring. CirpAnnals Manufacturing Technology, VOL: 46.1 , pp. 49-52. 1997.

[9] K..N. Strafford, J. Audy. Indirect monitoring of machinability in carbon steels by measurement of cutting forces. Journal of Materials Sciences, pp. $150-156$. 1997.

[10] Z. Aksoy. Orthogonal-ring dynamometer design for measuring cutting forces in turning operations. Proceedings of the Material and Production Symposium Conference, Dokuz Eyl"ul, Denizli Turkey, 1987.
M.Bourdim: This author became a member of NAUN in 2017, date of birth (Bab El Assa, Tlemcen - Algeria in 1961). License 1983, Magister 2007 and doctorate 2013 es-sciences of the normal high school of technical education of Oran Algeria: in mechanical engineering option manufacturing technology and currently research professor at the university Ahmed Zabana Relizane Algeria.

\section{Creative Commons Attribution License 4.0 (Attribution 4.0 International, CC BY 4.0)}

This article is published under the terms of the Creative Commons Attribution License 4.0

https://creativecommons.org/licenses/by/4.0/deed.en_US 